\title{
Extracorporeal Shock Wave Therapy for an Adolescent Patient with Calcific Tendinopathy of Posterior Tibial Tendon: A Case Report
}

\author{
Kazuya Ikoma, MD, PhD a Yusuke Hara, MD, PhD a Masahiro Maki, MD, PhD a \\ Suzuyo Ohashi, MD, PhD ${ }^{b}$ Keiichiro Ueshima, MD, PhD ${ }^{\text {a }}$ and Toshikazu Kubo, MD, PhD ${ }^{\text {a, b }}$
}

Background: We report a rare case of calcific tendinopathy in the posterior tibial tendon (PTT) at the navicular insertion. Case: Conservative treatments other than extracorporeal shock wave therapy (ESWT) were ineffective. Calcium deposition disappeared from the PTT on plain radiographs at 6 months after ESWT. Discussion: In this case, a 14-year-old boy with calcific tendinopathy of the PTT who had not benefited from conservative treatments was effectively treated using ESWT.

Key Words: calcific tendinopathy; calcium hydroxyapatite; extracorporeal shock wave therapy (ESWT); posterior tibial tendon

\section{INTRODUCTION}

Calcific tendinopathy is a condition that results from the deposition of calcium hydroxyapatite crystals in the tendons. We describe a case of calcific tendinopathy involving the posterior tibial tendon (PTT) at the navicular insertion for which extracorporeal shock wave therapy (ESWT) was effective.

\section{CASE}

For 2 years, a 14-year-old baseball player had experienced right medial foot pain without identifiable causes. The patient visited several outpatient clinics, where he was diagnosed with flat feet, painful os tibiale externum, and calcareous deposition in the medial side of the right foot (Fig. 1). He underwent the following conservative treatments: analgesics, avoidance of weight-bearing and sports activities, using arch support, and local injection of corticosteroids for 3 months. However, the patient complained of persistent pain. Subsequently, redness and swelling developed on the medial side of the right foot. The patient experienced gradual exacerbation of pain and experienced difficulty in exercising and walking. Therefore, he was referred to our outpatient clinic 2 years after the first onset of symptoms. Upon physical examination of the right foot, we observed redness, swelling, a feeling of warmth, and significant tenderness on the posterior tibial tendon (PTT), rather than the os tibiale externum. The visual analog scale (VAS) score was $85 \mathrm{~mm}$. The patient's score was 48 points and 48 points, respectively, using the Japanese Society of Surgery for Foot (JSSF) score ${ }^{1,2}$ and the American Orthopaedic Foot and Ankle Society (AOFAS) score. ${ }^{3)}$ The radiographs showed os tibiale externum and calcareous deposition in the right medial foot at the insertion point of the PTT (Fig. 2). Magnetic resonance imaging (MRI) showed a reduction in signal intensity as a result of calcification at the insertion of the PTT and bone marrow edema at the navicular region (Fig. 3). Initial treatment involved restricted activity and load bearing, administration of nonsteroidal anti-inflammatory drugs (NSAIDs, loxoprofen, two 100-mg tablets per day, for 1 month), and the wearing of arch support for 2 months. However, extracorporeal shock wave therapy (ESWT) was performed because the pain continued and the patient was unable to walk. ESWT was started

Received: August 17, 2017, Accepted: February 21, 2018, Published online: March 10, 2018

${ }^{a}$ Department of Orthopaedics and ${ }^{b}$ Rehabilitation Medicine, Graduate School of Medical Science, Kyoto Prefectural University of

Medicine, Kyoto, Japan

Correspondence: Kazuya Ikoma MD, PhD, 465 Kajii-cho, Kawaramachi-Hirokoji, Kamigyo-ku, Kyoto 602-8566, Japan,

E-mail:kazuya@koto.kpu-m.ac.jp

Copyright (C) 2018 The Japanese Association of Rehabilitation Medicine 

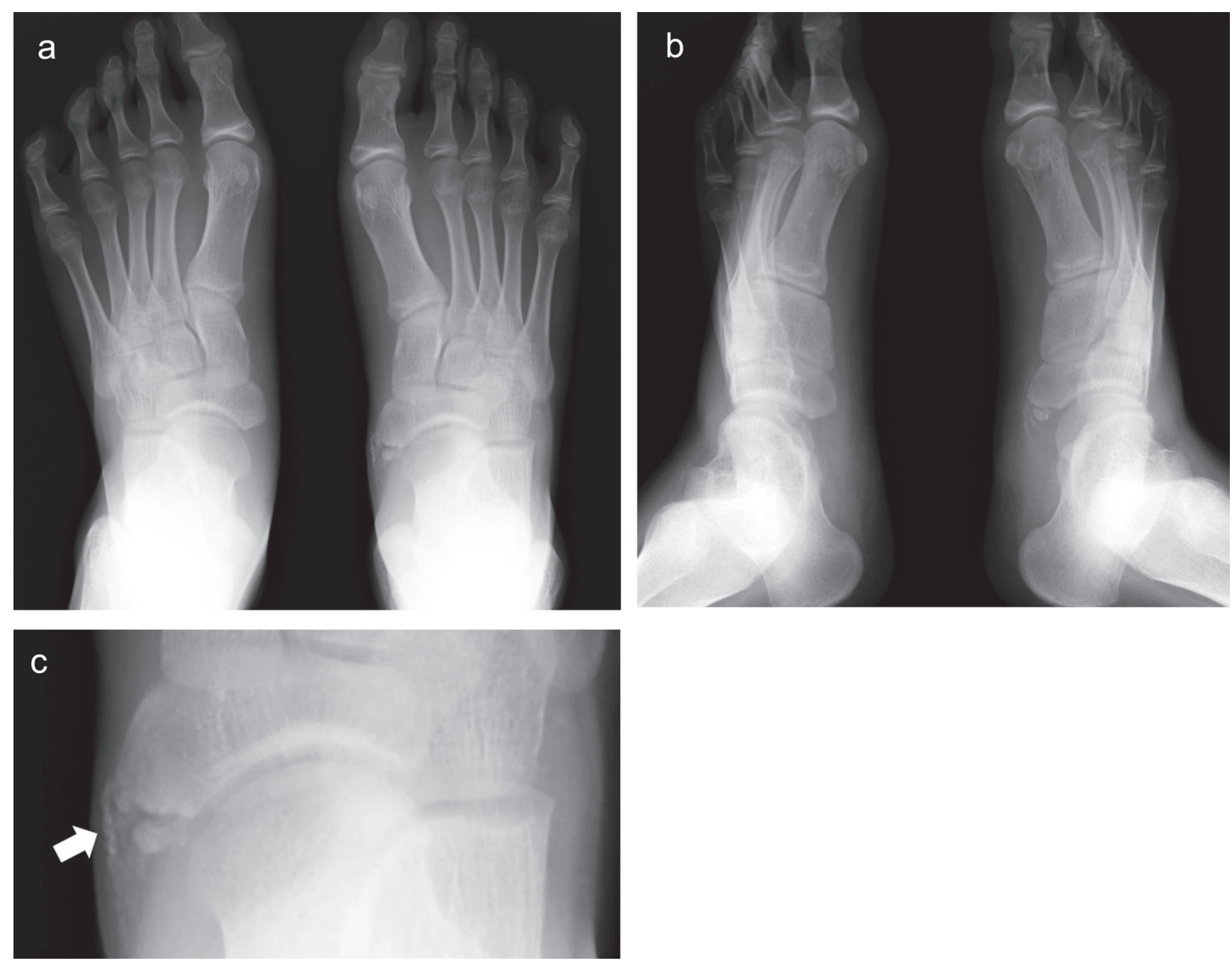

Fig. 1. Radiographs of bilateral feet at the first outpatient visit to another clinic. These images suggest os tibiale externum and calcareous deposition on anteroposterior (AP) view of bilateral feet (a). Oblique view of right foot (b) shows os tibiale externum and calcareous deposition. AP view of right foot (c) shows calcareous deposition.

from $0.03 \mathrm{~mJ} / \mathrm{mm}^{2}$ (the lowest energy level) and increased to $0.36 \mathrm{~mJ} / \mathrm{mm}^{2}$, which was the maximal level. Treatment was completed when the gross radiation energy reached 1300 $\mathrm{mJ} / \mathrm{mm}^{2}$. The pain improved on the second day and the gait pain disappeared within 1 week after ESWT. The VAS score improved to $10 \mathrm{~mm}$ in 4 weeks. However, the pain recurred 3 months after ESWT. During the patient's visit to our outpatient clinic, the VAS score was $57 \mathrm{~mm}$. Therefore, a second course of ESWT was performed with the same protocol as the first course of ESWT. The pain quickly disappeared after the second course of ESWT and the patient was able to walk on the second day. He was able to play tennis without pain after 3 months. The calcareous deposition had disappeared on radiographs taken 6 months after the second course of ESWT (Fig. 4). At present (2 years after the two courses of
ESWT), the patient is able to exercise. The VAS score has improved to $5 \mathrm{~mm}$ and the JSSF and AOFAS scores both increased to 95 points. Arch support can be worn without pain. Informed consent for the publication of this case report was obtained from the patient and his parent.

\section{DISCUSSION}

In the literature, calcific tendinopathy has been reported under various names, e.g., calcific peritendinitis, calcific bursitis, periarticular calcarea, and hydroxylapatite rheumatism. ${ }^{4}$ Generally, calcific tendinopathy occurs in the tendons around the shoulder and affects approximately $3 \%$ of adults. ${ }^{5)}$ This condition occurs in both men and women and has been observed mainly in the past 40-60 years. ${ }^{6)}$ More- 


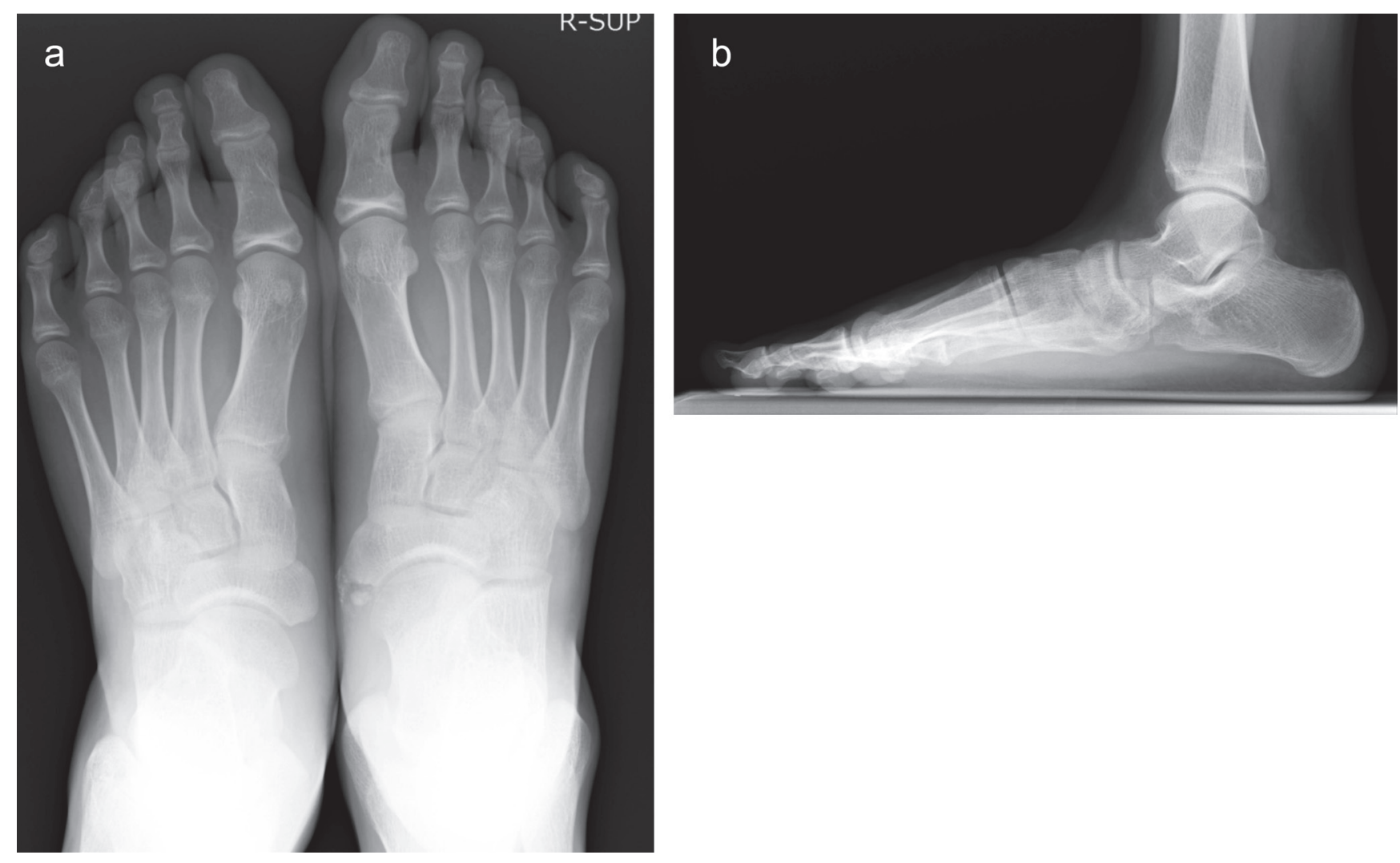

Fig. 2a, b. Radiographs of bilateral feet at the first visit to our outpatient clinic. There was calcareous deposition around the os tibiale externum.
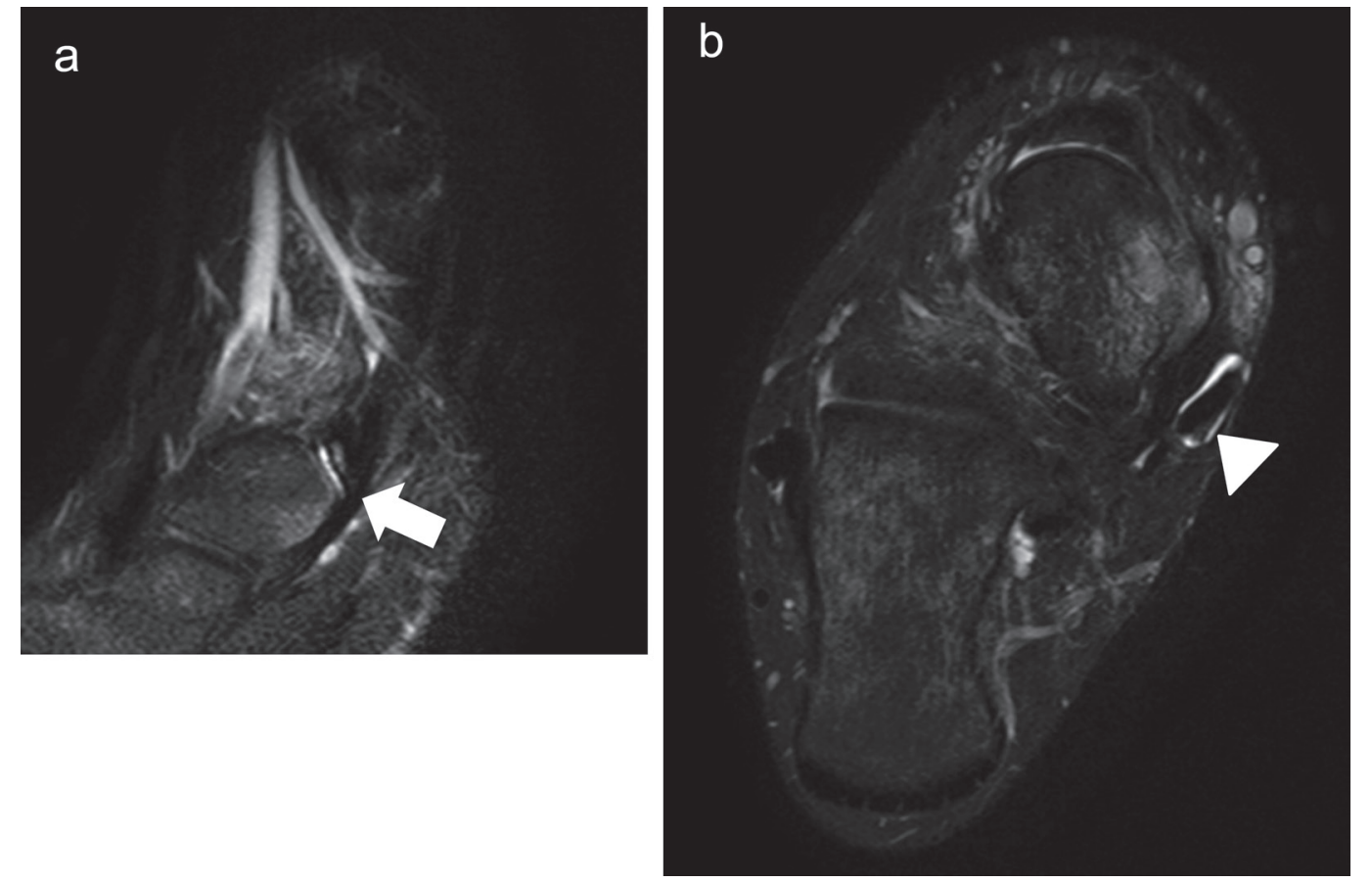

Fig. 3. T2-weighted MRI of the right foot on sagittal plane (a) and axial plane (b). MRI showed bone marrow edema, the navicular, os tibiale externum, and fluid around the posterior tibial tendon. 


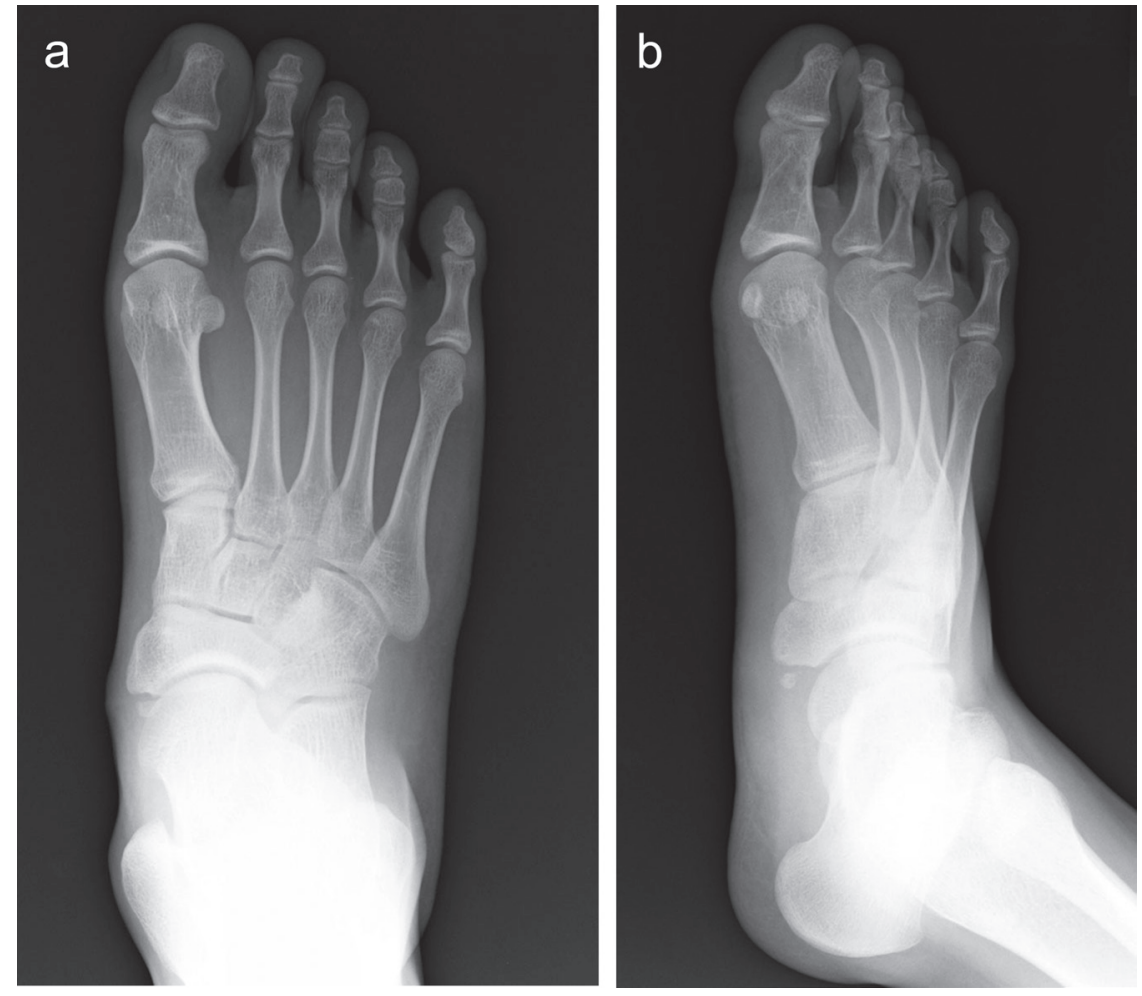

Fig. 4. Radiographs of the right foot in the standing position at final follow-up ( 2 years after ESWT) on AP view (a) and oblique view (b) of the right foot. The calcareous deposition had disappeared around the os tibiale externum.

over, calcific tendinopathy has been reported in many parts of the body other than the shoulder, but it rarely occurs in the foot, which reportedly accounts for approximately $1 \%$ of all cases. ${ }^{4)}$ The flexor tendon of the forefoot is the most common site of this disorder, when arising in the foot. Reports on similar cases in which calcific tendinopathy occurred in the insertion of PTT are extremely rare. To date, only four such cases have been reported, to the best of our knowledge (Table 1) ${ }^{7-10)}$ Differential diagnoses of calcific tendinopathy of the insertion of PTT include local infection, fracture, gout, pseudogout, and painful accessory navicular. The diagnosis of calcific tendinopathy is straightforward, and calcareous deposition in the insertion of PTT can be confirmed through plain radiographs. Such images of the calcareous deposition in symptomatic patients show cloudy calcium hydroxyapatite crystals in common calcific tendinopathy.

We observed similar findings in our patient during the subacute phase with relevant symptoms of calcific tendinopathy. This disorder is extremely rare, especially in a 14-year-old boy and in the part of the foot involved. It is possible that chronic inflammation in the accessory navicular bone may have induced calcific tendinopathy, because os tibiale exter- num was present as a developmental mechanism.

Conservative treatment strategies are commonly used for the treatment of calcific tendinopathy. In particular, local steroid injections are effective and surgery is generally not required. However, the optimal therapy has not yet been established because of the extreme rarity of this condition. We sequentially administered sufficient conservative treatments for the disorder using previously recommended medicines, but the symptoms did not improve.

ESWT may be more efficacious in treating calcific tendinopathy in the shoulder compared with initial conservative treatments. ${ }^{11-13)}$ Shock waves are acoustic waves associated with a sudden rise in pressure. They may be generated by electrohydraulic, electromagnetic, or piezoelectric devices. However, their interactions with tissues are not completely understood. The amount of energy released by the sonic pulse per unit area is expressed as an energy flux density in $\mathrm{mJ} / \mathrm{mm}^{2}{ }^{14)}$ Although there is no universal agreement on the threshold values, low-energy extracorporeal shock waves have an energy flux density below $0.08 \mathrm{~mJ} / \mathrm{mm}^{2}$, mediumenergy shock waves are from 0.08 to $0.28 \mathrm{~mJ} / \mathrm{mm}^{2}$, and high-energy shock waves are from 0.28 to $0.60 \mathrm{~mJ} / \mathrm{mm}^{2}{ }^{15}$ ) 
Table 1. Reports of calcific tendinopathy of the posterior tibial tendon

\begin{tabular}{|c|c|c|c|c|}
\hline Author & Age (years), sex & Image findings & Treatment & Therapeutic outcomes \\
\hline Delmi M (1995) & 38 , female & None & Surgical removal & $\begin{array}{l}\text { Walk for } 1 \text { hour with- } \\
\text { out a limp }\end{array}$ \\
\hline Kirschner S (1998) & 55 , female & $\begin{array}{l}\text { X-ray: calcific shadow } \\
\text { MRI-T2WI: high signal intensity in } \\
\text { PTT }\end{array}$ & Surgical removal & $\begin{array}{l}\text { Pain free, full ROM of } \\
\text { ankle }\end{array}$ \\
\hline Jakhere SG (2011) & 40 , male & $\begin{array}{l}\text { X-ray: calcific shadow } \\
\text { MRI-T1WI: thickening of PTT with } \\
\text { loss of normal hypointense signal } \\
\text { MRI-STIR: edema with overlying } \\
\text { subcutaneous tissues }\end{array}$ & $\begin{array}{l}\text { Pain killers, rest, } \\
\text { immobilization }\end{array}$ & $\begin{array}{l}\text { Resorption after } 1 \\
\text { month }\end{array}$ \\
\hline Harries L (2011) & 42 , female & $\begin{array}{l}\text { X-ray: calcific shadow } \\
\text { Ultrasound: hyperechoic structure in } \\
\text { distal portion of PTT }\end{array}$ & $\begin{array}{l}\text { NSAIDs, steroid } \\
\text { injection, rest, } \\
\text { crutches }\end{array}$ & Pain free after 2 weeks \\
\hline This report & 14 , male & $\begin{array}{l}\text { X-ray: calcific shadow } \\
\text { MRI-T1WI: thickening of PTT with } \\
\text { loss of normal hypointense signal } \\
\text { MRI-STIR: edema with overlying } \\
\text { subcutaneous tissues }\end{array}$ & $\begin{array}{l}\text { NSAIDs, rest, } \\
\text { immobilization, } \\
\text { ESWT }\end{array}$ & $\begin{array}{l}\text { Play tennis } 6 \text { months } \\
\text { later }\end{array}$ \\
\hline
\end{tabular}

MRI-T2WI, magnetic resonance imaging T2-weighted image; MRI-STIR, magnetic resonance imaging - short tau inversion recovery; ROM, range of motion.

The effects of ESWT on calcific tendonitis are currently unknown. However, its effects on focal regions include desensitization by the induction and enhancement of absorption due to microinjury, which in turn causes the destruction of free nerve endings. This effect of ESWT relieved the pain from calcific tendinopathy in the current patient. In addition, bone formation and angiogenic promotion occur as a result of the mechanical irritation of cells in the boundary region during the tendon repair response. ${ }^{15)}$ This explains why the absorption of calcific deposits did not occur immediately.

Because the symptoms had continued for over 2 years despite conservative treatments using previously prescribed medicines, we anticipated that the patient would benefit from the same ESWT treatment as had been administered to a different patient with calcific tendinopathy of the shoulder. Consequently, we pursued the case for ESWT treatment after consultation with the patient and his family. The treatment was very effective: the symptoms mostly disappeared after two sessions of ESWT, and the calcareous deposition had disappeared on x-ray images taken 6 months later. Therefore, ESWT was effective in treating calcific tendinopathy of the PTT. In this case, the symptoms persisted for about 2 years. Therefore, a long period elapsed between irradiation and calcium deposit absorption, and the symptoms recurred. In addition, we believe that the irradiation energy required for absorbing calcium deposits was the reason for requiring two irradiation courses. To minimize the possibility of recurrence and to reduce the load on the PTT after the second round of ESWT, the patient wore insoles with a medial wedge and refrained from exercise until the calcium deposits were absorbed.

A possible side effect of ESWT includes osteonecrosis at the head of the humerus in the shoulder, as described in two reports. ${ }^{16,17)}$ Osteonecrosis occurs between 6 months and 2 years after treatment. It is also important to pay attention to osteonecrosis of the navicular bone. However, we observed no evidence of osteonecrosis to a radiale on radiographic images in our case even 2 years after treatment. Indeed, careful observations in the future are necessary. In conclusion, ESWT was effective in treating the disorder in this case of calcific tendinopathy of the insertion of PTT that occurred in a 14-year-old boy, even though the patient was resistant to conservative treatment.

\section{CONFLICT OF INTEREST}

The authors declare that there is no conflict of interest regarding the publication of this article. 


\section{REFERENCES}

1. Niki H, Tatsunami S, Haraguchi N, Aoki T, Okuda R, Suda Y, Takao M, Tanaka Y: Development of the patientbased outcome instrument for the foot and ankle. Part 1: project description and evaluation of the outcome instrument version 1. J Orthop Sci 2011;16:536-555 DOI:10.1007/s00776-011-0130-7. PMID:21755375

2. Niki H, Tatsunami S, Haraguchi N, Aoki T, Okuda R, Suda Y, Takao M, Tanaka Y: Development of the patient-based outcome instrument for foot and ankle: part 2: results from the second field survey: validity of the outcome instrument for the foot and ankle version 2. J Orthop Sci 2011;16:556-564 DOI:10.1007/s00776011-0131-6. PMID:21755374

3. Kitaoka HB, Alexander IJ, Adelaar RS, Nunley JA, Myerson MS, Sanders M: Clinical rating systems for the ankle-hindfoot, midfoot, hallux, and lesser toes. Foot Ankle Int 1994;15:349-353 DOI:10.1177/107110079401500701. PMID:7951968

4. Bossi R: Peritendinitis calcarea with multiple foci in the finger joints of a young subject. Br J Radiol 1954;27:692-695 DOI:10.1259/0007-1285-27-324-692. PMID:13209030

5. Holt P, Keats T: Calcific tendinitis: a review of the usual and unusual. Skeletal Radiol 1993;22:1-9 DOI:10.1007/ BF00191518. PMID:8430339

6. Fam AG, Rubenstein J: Hydroxyapatite pseudopodagra. A syndrome of young women. Arthritis Rheum 1989;32:741-747 DOI:10.1002/anr.1780320612. PMID:2544186

7. Delmi M, Kurt AM, Meyer JM, Hoffmeyer P: Calcification of the tibialis posterior tendon: a case report and literature review. Foot Ankle Int 1995;16:792-795 DOI:10.1177/107110079501601209. PMID:8749351

8. Kirschner S, Raab P, Krauspe R: Calcifying tendinitis of the tibialis posterior: a case report. Foot Ankle Surg 1998;4:233-236 DOI:10.1046/j.14609584.1998.00093.x.

9. Jakhere SG, Yadav D, Vasudeo Bharambay H: Acute calcific tendinitis of tibialis posterior tendon
(TPT): A rare site of involvement. Eur J Radiol Extra 2011;77:e17-e20 DOI:10.1016/j.ejrex.2010.10.006.

10. Harries L, Kempson S, Watura R: Calcific tendonitis of the tibialis posterior tendon at the navicular attachment. J Radiol Case Rep 2011;5:25-30. PMID:22470798

11. Louwerens JK, Veltman ES, van Noort A, van den Bekerom MP: The effectiveness of high-energy extracorporeal shockwave therapy versus ultrasoundguided needling versus arthroscopic surgery in the management of chronic calcific rotator cuff tendinopathy: a systematic review. Arthrosc The J Arthroscopic Relat Surg 2016;32:165-175 DOI:10.1016/j. arthro.2015.06.049. PMID:26382637

12. Rompe JD, Rumler F, Hopf C, Nafe B, Heine J: Extracorporal shock wave therapy for calcifying tendinitis of the shoulder. Clin Orthop Relat Res 1995;196-201. PMID:7497669

13. Gerdesmeyer L, Wagenpfeil S, Haake M, Maier M, Loew M, Wörtler K, Lampe R, Seil R, Handle G, Gassel S, Rompe JD: Extracorporeal shock wave therapy for the treatment of chronic calcifying tendonitis of the rotator cuff: a randomized controlled trial. JAMA 2003;290:2573-2580 DOI:10.1001/jama.290.19.2573. PMID:14625334

14. Ogden JA, Tóth-Kischkat A, Schultheiss R: Principles of shock wave therapy. Clin Orthop Relat Res 2001;8-17 DOI:10.1097/00003086-200106000-00003. PMID:11400898

15. Rompe JD, Kirkpatrick CJ, Küllmer K, Schwitalle M, Krischek O: Dose-related effects of shock waves on rabbit tendo Achillis: a sonographic and histological study. J Bone Joint Surg Br 1998;80:546-552 DOI:10.1302/0301-620X.80B3.8434. PMID:9619954

16. Durst HB, Blatter G, Kuster MS: Osteonecrosis of the humeral head after extracorporeal shock-wave lithotripsy. J Bone Joint Surg Br 2002;84:744-746 DOI:10.1302/0301-620X.84B5.12282. PMID:12188497

17. Liu HM, Chao CM, Hsieh JY, Jiang CC: Humeral head osteonecrosis after extracorporeal shock-wave treatment for rotator cuff tendinopathy. A case report. J Bone Joint Surg Am 2006;88:1353-1356 DOI:10.2106/ JBJS.E.00868. PMID:16757772 